\title{
Trabalho docente em escolas rurais: \\ pesquisa e diálogos em tempos de pandemia
}

\section{The work of teaching in rural schools:}

research and dialogue in times of pandemic

\section{Labor docente en escuelas rurales:}

Investigación y diálogo en tiempos de pandemia

\section{ELIZEU CLEMENTINO DE SOUZA*}

*Universidade do Estado da Bahia, Salvador-BA, Brasil.

\section{MICHAEL DAIAN PACHECO RAMOS}

Universidade do Estado da Bahia, Salvador-BA, Brasil.

\begin{abstract}
RESUMO: Este artigo resulta da pesquisa Trabalho docente em tempos de pandemia e visa compreender os efeitos das medidas de isolamento social sobre o trabalho dos professores da educação do campo. A coleta de dados ocorreu através de questionário autoaplicado on-line e 892 respondentes afirmaram que atuam em escolas rurais. Os resultados apontam que o contexto da pandemia evidencia as desigualdades sociais do país, em particular nos espaços rurais. A pequena experiência dos docentes com o ensino remoto, a ausência de formação, a falta de recursos tecnológicos e a dificuldade em manuseá-los revelam essas desigualdades.
\end{abstract}

Palavras-chave: Trabalho docente. Escolas rurais. Pandemia.

ABSTRACT: This article is the result of the research Trabalho docente em tempos de pandemia and aims to understand the effects of social

* Pesquisador 1 do Conselho Nacional de Desenvolvimento Científico e Tecnológico. Doutor em Educação pela Universidade Federal da Bahia. Professor titular da Universidade do Estado da Bahia (UNEB). Coordenador do Grupo de Pesquisa (Auto)biografia, Formação e História Oral (GRAFHO). E-mail: <esclementino@uol.com.br>.

** Doutor em Educação e Contemporaneidade pela Universidade do Estado da Bahia (UNEB). Professor assistente da UNEB. Membro do Grupo de Pesquisa (Auto)biografia, Formação e História Oral (GRAFHO). E-mail:<michaeluneb@gmail.com>. 
isolation measures on the work of rural education teachers. Data collection took place through a self-administered online questionnaire, and 892 respondents stated that they work in rural schools. The results show that the context of the pandemic highlights the country's social inequalities, particularly in rural areas. The teachers' small experience with remote education, the lack of training, the lack of technological resources and the difficulty in handling them, reveal these inequalities.

Keywords: The work of teaching. Rural schools. Pandemic.

RESUMEN: Este artículo es el resultado de la investigación Trabajo docente en tiempos de pandemia y apunta a comprender los efectos de las medidas de aislamiento social en el trabajo de los profesores de educación rural. La recolección de datos se realizó a través de un cuestionario autoadministrado en línea y 892 encuestados afirmaron que trabajan en escuelas rurales. Los resultados muestran que el contexto de la pandemia destaca las desigualdades sociales del país, particularmente en las áreas rurales. La escasa experiencia de los docentes con la educación a distancia, la falta de formación, la falta de recursos tecnológicos y la dificultad para manejarlos revelan estas desigualdades.

Palabras clave: Trabajo docente. Escuelas rurales. Pandemia.

\section{Apontamentos iniciais}

pandemia que se atravessa por conta do novo coronavírus (Covid-19) tem
impactado fortemente os sistemas educacionais em todo o mundo. Somada às
profundas questões pedagógicas relativas ao ensino remoto, o debate circunda reflexões sobre infraestrutura, condições sociais e de saúde da comunidade escolar, formação e condições de trabalho dos docentes que se encontram na linha de frente desse processo de reorganização escolar.

A pesquisa Trabalho docente em tempos de pandemia, realizada pelo Grupo de Estudos Sobre Política Educacional e Trabalho Docente (Gestrado) da Universidade Federal de Minas Gerais (UFMG), em parceria com a Confederação Nacional dos Trabalhadores em Educação (CNTE), buscou conhecer os efeitos das medidas de isolamento social, quais atividades estão sendo desenvolvidas e em que condições, em função da pandemia da Covid-19 sobre o trabalho docente na educação básica nas redes públicas de ensino no Brasil. 
Esta pesquisa foi desenvolvida através de um survey, utilizando uma amostragem não probabilística e a coleta de dados ocorreu por meio de questionário autoaplicado on-line, disponibilizado na plataforma Google Forms, entre os dias 8 e 30 de junho de 2020. O questionário foi composto de cinco blocos de questões: a) Informações básicas; b) Condições de trabalho; c) Relação com os estudantes; d) Formação para o ensino remoto; e e) Sentimentos em relação ao novo contexto de trabalho. O tempo médio de resposta foi em torno de 15 minutos.

Foram obtidas 15.654 respostas válidas de professores das redes públicas da educação básica de todo Brasil. Especificamente, os respondentes que atuam na educação do campo correspondem a 892 professores, o que equivale a 5,7\% da amostra total da pesquisa. Os dados apresentados neste texto referem-se exclusivamente aos docentes respondentes que atuam na educação do campo.

\section{Trabalho docente em contexto rural: reflexões necessárias ao contexto rural}

De acordo com a Pesquisa Nacional por Amostra Domiciliar (Pnad), em 2014, há um percentual significativo de pessoas que residem em áreas rurais do Brasil cujo total ultrapassa mais de 31 milhões de habitantes. A região Nordeste possui os maiores números absolutos de pessoas vivendo em localidades rurais, em torno de 15 milhões, cerca da metade dos habitantes do espaço rural do Brasil. Em termos absolutos, a Bahia apresenta a maior população rural do país, com cerca de 4 milhões de pessoas (PNAD, 2014).

Diante desse panorama expressivo, consideramos fundamental a necessidade de pesquisas sobre o contexto rural, especialmente em relação aos processos educacionais. Particularmente, a dimensão da educação básica nas localidades rurais, de acordo com o Censo Escolar de 2019, é de 5,3 milhões de matrículas, mais de 333 mil docentes, distribuídos em cerca de 55 mil escolas, compostas de mais de 300 mil turmas (INEP, 2020).

Tal expressividade numérica, para além da singularidade das pessoas que habitam territórios rurais, reforça o que afirmam Souza e demais autores (2018), quando enfatizam que os estudos e pesquisas sobre os espaços rurais tornam-se relevantes pelo seu valor heurístico, no intuito de compreendermos a dinâmica dessas localidades.

\footnotetext{
Nessa perspectiva, ao observarmos o contingente populacional residente em áreas rurais ou em vilas e pequenas cidades que têm seu cotidiano atrelado ao rural, bem como em relação às vivências, experiências e modos de ver o mundo que tais populações possuem, torna-se imprescindível a ampliação dos estudos sobre ruralidades na atualidade, tendo em vista que é preciso contribuir, sobretudo, para o melhor entendimento das relações entre o espaço vivido (rural) e a formação de tais indivíduos, seja no entendimento de si mesmo, do outro e do mundo (SOUZA, et. al., 2018, p. 22-23).
} 
Conforme sinalizam os autores, reforçamos nossa compreensão do rural como espaço diversificado, multicultural, contudo, apresenta singularidades, particularidades e especificidades, haja vista a diversidade de paisagens, culturas, histórias e práticas sociais. Essa compreensão também reverbera nos contextos educativos em espaços rurais do País.

Santos (2015), a partir dos seus estudos sobre a escola rural, constata alguns desafios que necessitam ser enfrentados e superados - e um deles é a prevalência de representações negativas sobre a escola rural. A despeito das representações negativas e preconceituosas que recaem sobre as escolas rurais, seus professores e alunos, fruto de uma visão profundamente conservadora, outras análises apresentam uma nova forma de compreendê-las, passando de espaços entendidos como problema, para uma solução - "porta voz" do sentir da população, ademais trata-se de "uma escola portadora de futuro" (AMIGUINHO, 2008).

Diversos estudos (BOF, 2006; INEP, 2007; ANTUNES-ROCHA, HAGE 2010; SOUSA, 2015; SOUSA, 2020; RAMOS, 2020) sinalizam as precárias condições de trabalho, a ausência de infraestrutura, de serviços básicos e os baixos índices educacionais das escolas rurais. Dessa forma, torna-se importante refletir como os professores que atuam em escolas rurais vêm enfrentando questões educacionais devido à pandemia do coronavírus.

A suspensão das atividades de ensino presenciais nas unidades educacionais, por conta da pandemia, revela um impacto ainda maior para as populações que vivem nos espaços rurais, pois a escola, nessas comunidades, tem importância fundamental que ultrapassa o significado pedagógico, articulando-se como elemento de política social. Ao destacar o lugar assumido pela escola e sua função no território rural, afirma Amiguinho que

a escola pode ter neste campo um papel preponderante por mais pequena que possa ser. Tal sucede justamente pelo interesse comunitário que a escola suscita, face ao esvaziamento institucional dos territórios. Assim sendo reequaciona-se o significado institucional da escola, não apenas com estrutura de ensino, ou espaço de instrução mas como elo de política social (AMIGUINHO, 2008, p. 30).

Para além das funções pedagógicas que exercem a escola no território rural, cabe observar, conforme teoriza Moreira (2005), que as relações particulares que os indivíduos que vivem em espaços rurais mantêm com o seu entorno produzem objetividades, subjetividades, espiritualidades e sensibilidades que compõem o seu modo de vida, a compreensão de si e do mundo. Sendo assim, o conjunto desses processos sociais relaciona-se com o que se denomina de ruralidades, contribuindo para fundamentar a identidade social dos sujeitos que vivem em contextos rurais. Neste trabalho, a ruralidade é concebida como uma construção social, um modo de ser e viver que interpela uma forma singular de inserção nos diferentes processos sociais e históricos.

Nesse movimento, Souza e demais autores (2017) afirmam que o esforço em desenvolver pesquisas com escolas rurais visa minimizar os processos de exclusão sofridos 
pelos sujeitos - alunos e professores -, além de oportunizar intercâmbios férteis entre sujeitos diversos da comunidade, mediante socialização de memórias e narrativas de vida dos atores socais, suas configurações, modos de vida e também sobre as condições objetivas e subjetivas do trabalho docente, das condições físicas das escolas e de mobilidades dos estudantes de seus territórios para escolas urbanas, para que possam prosseguir com seus estudos.

Portanto, analisar o trabalho de professores inseridos em contextos rurais perpassa pela ideia de compreender as especificidades do espaço rural, que deve ser entendido, ao mesmo tempo, como espaço físico, lugar onde se vive, onde se produz a vida e se aprende, configurando-se através de especificidades socioespaciais e simbólicas e, também, mediante significados outros, construídos sobre o mundo da vida no território rural. Dessa forma, compreender a educação e os processos de ensino que ocorrem em contextos rurais torna-se elemento fundamental pois, historicamente, diversas questões relacionadas à escola rural foram silenciadas e negligenciadas.

Essa ressignificação do rural vem sendo instituída pelo conjunto de dispositivos legais e com diversas ações políticas dos movimentos sociais e sindicais em contextos rurais, bem como outras entidades e organizações, que buscam problematizar a ideia do rural como um lugar de atraso.

O documento Panorama da Educação do Campo, desenvolvido pelo Instituto Nacional de Pesquisas Educacionais Anísio Teixeira (INEP, 2007), sintetizou como sendo as principais questões que afetam a educação do campo: a insuficiência e a precariedade das instalações físicas da maioria das escolas; as dificuldades de acesso dos professores e alunos às escolas; a falta de professores habilitados e efetivados; currículo escolar que privilegia uma visão urbana de educação e desenvolvimento; a ausência de assistência pedagógica e supervisão escolar nas escolas rurais; o predomínio de classes multisseriadas com educação de baixa qualidade; a falta de atualização das propostas pedagógicas das escolas rurais; o baixo desempenho escolar dos alunos e elevadas taxas de distorção idade-série; os baixos salários e sobrecarga de trabalho dos professores; a necessidade de reavaliação das políticas de nucleação das escolas; a implementação de calendário escolar adequado às necessidades do contexto rural (INEP, 2007).

Torna-se necessário levar em consideração a realidade desses estudantes para articular com práticas pedagógicas que dialoguem com a heterogeneidade e a diversidade nas salas de aula, ao tempo em que é importante também reconhecer os desafios enfrentados pelos professores e alunos. Deve-se pensar o trabalho docente, tanto de escolas urbanas quanto rurais, que atendam às necessidades de alunos que habitam as diversas ruralidades, de modo que garantam as especificidades do modo particular de ser e de viver dos estudantes.

De acordo com Almeida, 
muitas são as adversidades que acompanham a educação rural. Poucas e precárias escolas, distantes umas das outras, dificuldades de comunicação, ausência de orientação metodológica e didática, falta de verbas públicas na escolarização, deficiência na formação de professores, currículos por vezes inadequados, poucos materiais pedagógicos, falta de livros, entre outros (2005, p. 286).

As insuficientes condições de trabalho apresentadas por Almeida (2005), Antunes-Rocha e Hage (2010), Pereira Junior (2017) revelam um contexto precário nas escolas que podem acarretar baixos índices de aprendizagem. Souza e demais autores (2018) afirmam categoricamente que o desenho da educação rural brasileira é composto de infraestrutura inadequada, estradas de difícil acesso, transportes impróprios e muitos professores sem formação específica, além de relações precárias de trabalho, marcadas por contratos terceirizados e rotatividade docente.

Pereira (2008) desenvolveu uma pesquisa sobre as condições de funcionamento das escolas rurais do município de Bujaru no estado do Pará. A autora aponta que os problemas enfrentados pela comunidade escolar se relacionam com: a atuação em classes multisseriadas; falta de mobiliário, equipamento e materiais didáticos; falta de transporte escolar; condições precárias de infraestrutura e falta de pessoal docente.

Alerta a autora que nas escolas rurais analisadas há uma precariedade de espaços internos e externos - sala de aula, cozinha, biblioteca, sala do professor, almoxarifado, banheiros, pátios etc., de recursos pedagógicos - cadeiras, quadro, giz, materiais didáticos etc., e contratação de pessoal - porteiro, merendeira, auxiliar de limpeza etc.. Essas condições adversas são apontadas pela autora como processos de intensificação do trabalho docente, acarretando danos pessoais (como a saúde do docente) e para o processo de ensino e aprendizado dos alunos.

Sousa (2015) desenvolveu um estudo sobre as condições de trabalho docente de professoras de classes multisseriadas do contexto rural do Território do Baixo Sul Baiano, com o intuito de compreender os modos como os docentes produzem a profissão. A autora analisou aspectos concernentes à formação, ingresso na profissão, contrato de trabalho, remuneração, condições materiais, estrutura física e de apoio, jornada de trabalho e condições de precarização a que estão submetidas as professoras de classes multisseriadas das escolas rurais.

As dificuldades com os recursos materiais também foram evidenciadas na pesquisa de Sousa (2015), quando 43\% dos professores afirmaram estar pouco satisfatórios ou insatisfatórios os recursos materiais disponíveis. Os docentes revelaram as dificuldades enfrentadas nas escolas, pois tiveram até que improvisar o mobiliário básico, mesas e cadeiras, para o desenvolvimento do seu trabalho.

A ausência e/ou precariedade de políticas públicas ganha destaque neste contexto de pandemia à medida que se constata a carência de uma melhor infraestrutura e 
manutenção dos prédios, inadequado e limitado material didático-pedagógico, falta de projetos e ações de formação de professores, dentre outros.

\section{O trabalho docente e a pandemia}

A análise das informações contidas nas respostas ao questionário por parte dos 892 docentes da educação básica das redes públicas que atuam em escolas rurais refere-se às características demográficas, à vinculação profissional, à utilização de tecnologia, docentes com aulas suspensas e ao desenvolvimento de atividades remotas, implicando investimentos pessoais e o movimento de autorresponsabilização docente, acentuado ainda mais no cenário pandêmico.

Obtivemos respostas dos professores de todos os estados da Federação, possibilitando coletar dados sobre a situação do trabalho remoto em escolas rurais no contexto da pandemia do Covid-19. Dois estados tiveram destaque com mais de 100 respondentes (Mato Grosso e Paraná); por outro lado, o estado do Rio de Janeiro apresentou apenas três respondentes.

\section{Gráfico 1: Distribuição dos docentes segundo o sexo e a faixa etária}

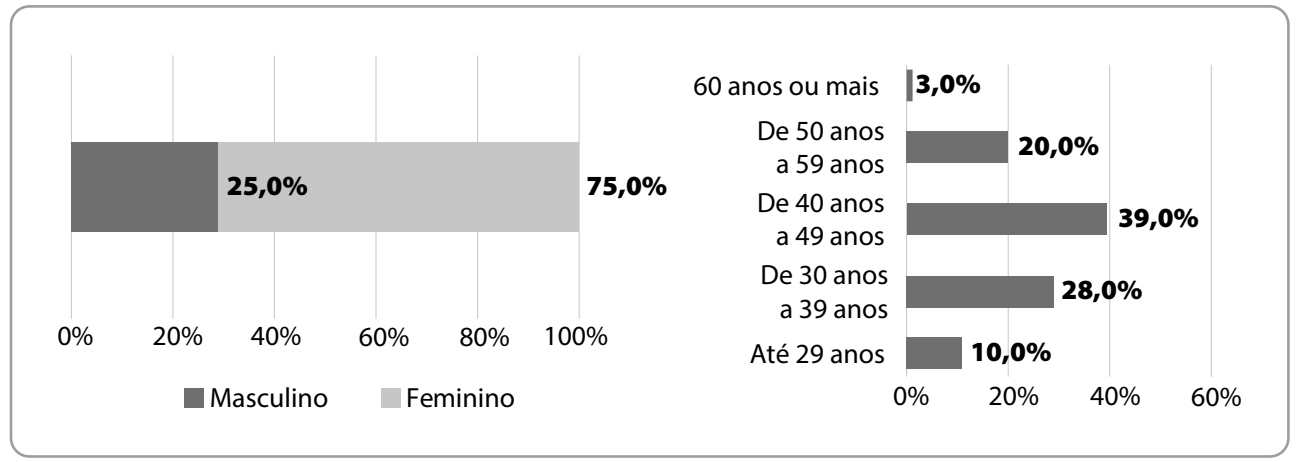

Fonte: Base de dados da pesquisa Trabalho docente em tempos de pandemia do Gestrado, 2020.

O gráfico 1 revela que as mulheres representam 75\% (663) dos respondentes e os homens 25\% (227). O universo docente é predominantemente feminino, acompanhando a tendência dos dados nacionais (INEP, 2020) e os resultados de outros estudos (UNESCO, 2004; INEP, 2009; OLIVEIRA; VIEIRA, 2012; RAMOS, 2020).

Dois terços (67\%) dos docentes participantes da pesquisa possuem idade entre $30 \mathrm{a}$ 49 anos. Quando analisamos a faixa etária, observa-se uma prevalência do percentual de docentes acima de 40 anos (39\%) e uma pequena proporção de docentes na faixa etária abaixo dos 29 anos (10\%) (Gráfico 1$)$. 
Dessa forma, os dados apresentados corroboram com a tendência dos resultados de diversos estudos sobre o perfil dos professores, ainda que esses trabalhos tenham sido realizados com docentes de escolas urbanas (INEP, 2007; OLIVEIRA; VIEIRA, 2012; FLEURI, 2015; CARVALHO, 2018; INEP, 2020).

\section{Gráfico 2: Distribuição dos docentes quanto a vinculação profissional}

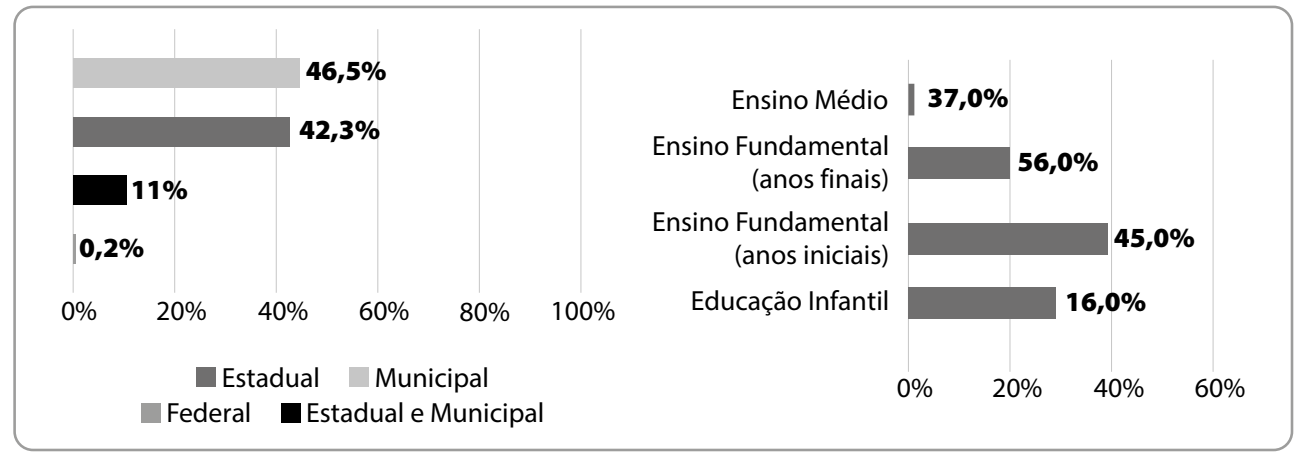

Fonte: Base de dados da pesquisa Trabalho docente em tempos de pandemia do Gestrado, 2020.

Observamos que $90 \%$ dos docentes atuam exclusivamente em uma única rede de ensino. A maioria (46,5\%) dos professores trabalha, exclusivamente, na rede municipal, seguido de $42,3 \%$ na rede estadual e $0,2 \%$ na esfera federal. Nenhum deles possui vínculo nas três redes de ensino, concomitantemente, e apenas 11\% trabalham na rede municipal e na estadual (Gráfico 2).

Mais da metade dos docentes (56\%) atua em apenas uma etapa/subetapa da educação básica, sendo que 56\% revelaram trabalhar nos anos finais do ensino fundamental. Em seguida, 45\% afirmam trabalhar nos anos iniciais do ensino fundamental e 37\% no ensino médio. O menor percentual ficou com os docentes que atuam na educação infantil, representando apenas $16 \%$ dos respondentes.

A prevalência de vínculo profissional em apenas uma rede de ensino, em particular a esfera municipal, e a predominância de atuação no ensino fundamental acompanham os resultados de estudos sobre o perfil de professores que atuam em escolas rurais (BOF, 2006; SOUZA, RAMOS, 2019; INEP, 2020).

As tecnologias digitais, anteriormente à pandemia, já se encontravam cada vez mais entrelaçadas ao cotidiano dos professores, contudo, com a suspensão das aulas presenciais, em decorrência do isolamento social resultante das medidas de prevenção à Covid-19, a utilização e manejo das tecnologias tornaram-se necessidade básica.

O cenário pesquisado revelou o caráter de novidade advindo da realização de aulas remotas, com caráter à distância. Ademais, evidenciou também a ausência de experiência nesse quesito. Como podemos observar no Gráfico 3, 87,3\% dos docentes da educação 
do campo não possuíam experiência anterior ministrando aulas à distância no formato remoto. Nesse sentido, apenas 12,7\% dos professores já possuíam experiência anterior com o ensino remoto.

\section{Gráfico 3: Distribuição dos docentes quanto a experiência anterior com o trabalho remoto}

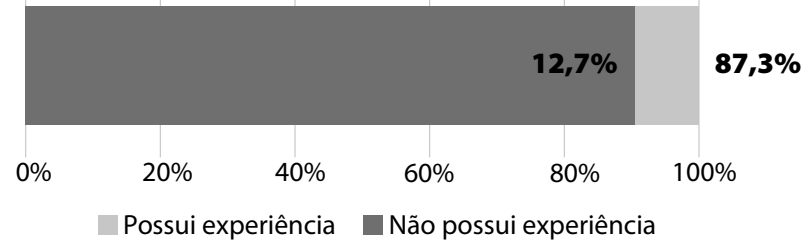

Fonte: Base de dados da pesquisa Trabalho docente em tempos de pandemia do Gestrado, 2020.

As medidas de distanciamento social provocaram novas dinâmicas no trabalho dos professores. A oferta do ensino remoto tem sido uma alternativa apontada por várias unidades educacionais. Nesse formato, há uma utilização de recursos tecnológicos pouco comuns nas aulas presenciais, acarretando uma novidade e desafios para a maioria dos docentes. Essa afirmação se concretiza quando apenas 30\% dos entrevistados afirmam possuir facilidade para o seu uso. Cerca de $21 \%$ dos docentes relatam sentir dificuldade no manuseio com as tecnologias digitais e metade afirma que não sentiu dificuldade e nem facilidade com as tecnologias digitais (Gráfico 4).

\section{Gráfico 4: Distribuição dos docentes quanto a formação e habilidades para lidar com as tecnologias digitais}

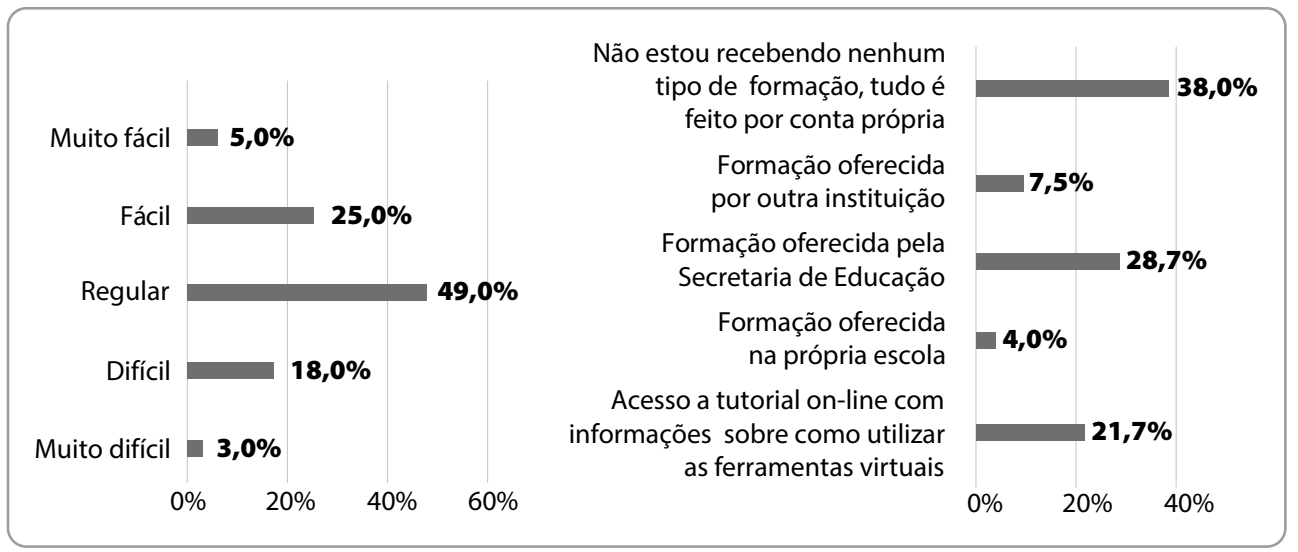

Fonte: Base de dados da pesquisa Trabalho docente em tempos de pandemia do Gestrado, 2020. 
As dificuldades podem ser mais bem compreendidas, pois a maioria dos professores (38\%) não está recebendo nenhum tipo de formação, sendo as atividades realizadas por conta própria e gerando, ainda mais, autorresponsabilização, em função da precarização da formação e das condições de trabalho. Entre os professores que afirmaram ter participado de atividades de formação para o uso de tecnologias digitais, a maior parte (28,7\%) afirma que essas atividades são oferecidas pelas secretarias de educação. Uma parcela significativa de docentes, cerca de $22 \%$, está buscando informações em tutorial on-line com informações sobre como utilizar as ferramentas virtuais (Gráfico 5).

É notório, a partir dos dados expostos, que os docentes têm tomado a direção de seu processo formativo para dar conta das dificuldades e desafios no acesso às tecnologias digitais de forma remota, o que tem implicado sobrecarga de trabalho, para além da elaboração de atividades didáticas enviadas aos alunos e, também, exigências colocadas no processo de planejamento das aulas remotas, sem considerar a dificuldade de acesso à internet e a equipamentos que, muitas vezes, não atendem às demandas e exigências postas com a pandemia.

\section{Gráfico 5: Distribuição dos docentes quanto a realização de atividades remotas devido à Covid-19}

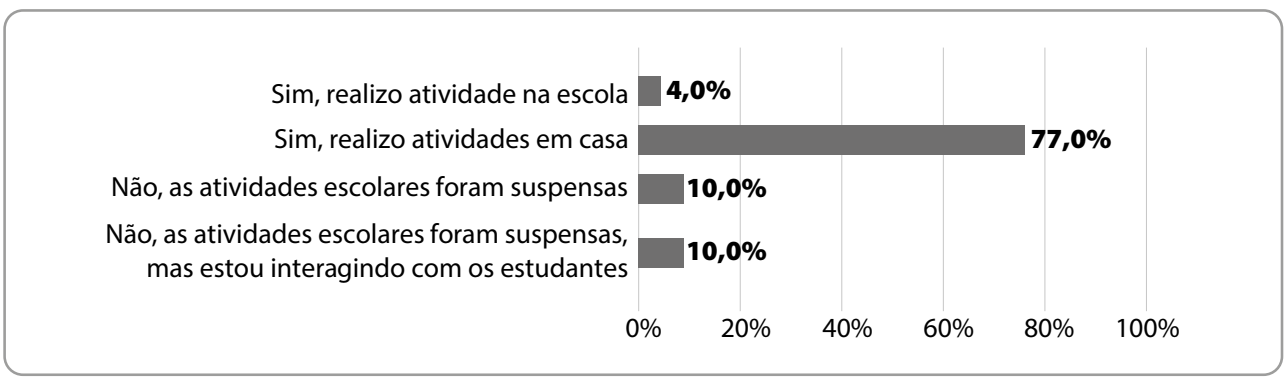

Fonte: Base de dados da pesquisa Trabalho docente em tempos de pandemia do Gestrado, 2020.

Quando questionados sobre a situação atual de trabalho, a maioria (81\%) dos professores afirma desenvolver atividades remotas, sendo que a grande maioria (77\%) as realiza em casa e apenas $4 \%$, na escola. Em torno de $10 \%$ dos docentes sinalizaram que não estão realizando nenhuma atividade, ao tempo que outros $10 \%$ sinalizaram que, mesmo não realizando atividades escolares, continuam mantendo algum tipo de interação com os estudantes (Gráfico 5).

Mais de 700 docentes estão realizando atividades remotas - na escola ou em casa -e a maioria (82\%) afirma que possui recursos tecnológicos para o desenvolvimento dessas atividades à distância. Observa-se que 75\% dos professores utilizam o telefone celular na realização das aulas à distância. Em seguida, aparece o notebook, utilizado por 58\% 
dos professores. Entre os dispositivos avaliados, o tablet foi o menos utilizado (4\%) pelos docentes no desenvolvimento de aulas remotas (Gráfico 6).

\section{Gráfico 6: Distribuição dos docentes que possuem recursos para ministrar aulas remotas}

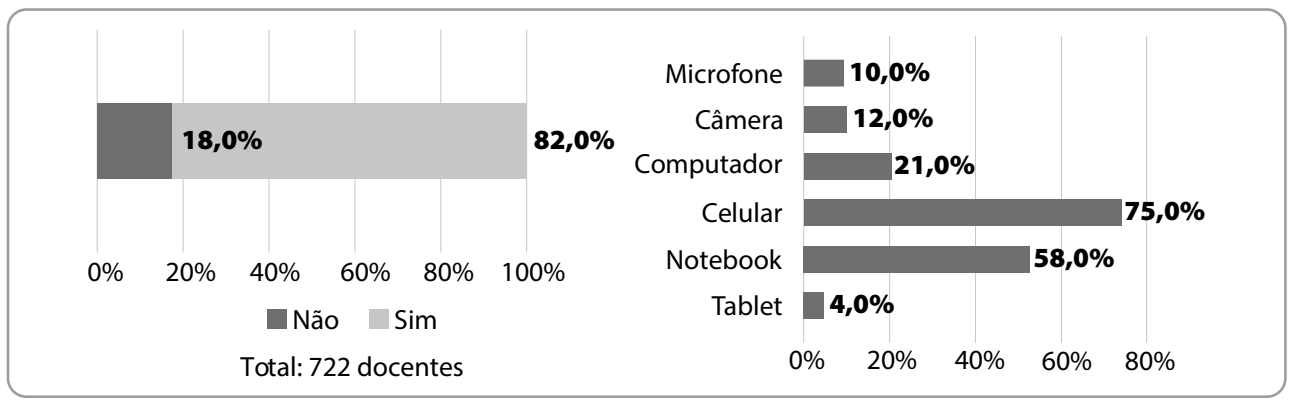

Fonte: Base de dados da pesquisa Trabalho docente em tempos de pandemia do Gestrado, 2020.

A pesquisa observou também a disponibilidade dos recursos tecnológicos na preparação e desenvolvimento das aulas remotas e observou que, dos mais de 500 professores que possuem dispositivos para ministrar aulas remotas, pouco mais da metade (55\%) afirma que compartilha esses recursos com outras pessoas no domicílio; a outra parte (45\%) faz uso exclusivo.

Obtivemos informações sobre o acesso à internet apenas daqueles professores que estão desenvolvendo atividades remotas (594 professores) e a maioria (64\%) possui internet banda larga. Em seguida, 27\% dos professores afirmam que possuem plano de dados pelo celular. Apenas 1\% sinalizou que não possui internet em casa (Gráfico 7).

\section{Gráfico 7: Distribuição dos docentes quanto ao acesso à internet}

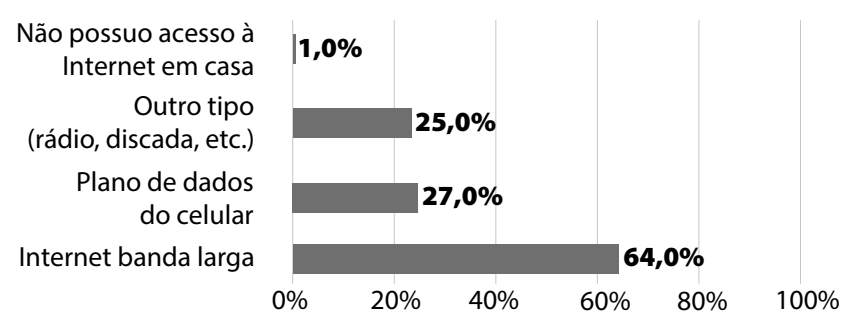

Fonte: Base de dados da pesquisa "Trabalho docente em tempos de pandemia" do Gestrado, 2020.

Outro aspecto avaliado na pesquisa é o tempo de trabalho na preparação das aulas à distância em comparação com as aulas presenciais. A grande maioria (84\%) dos docentes 
considera que a dedicação de suas horas de trabalho para a preparação das aulas remotas aumentou em relação à preparação das aulas presenciais. Para um pequeno percentual de professores (11\%), não há diferença em suas horas de trabalho preparando aula entre o formato presencial e remoto. Apenas $5 \%$ dos professores afirmaram que houve uma diminuição de seu tempo na preparação das aulas no contexto de aulas à distância (Gráfico 8).

\section{Gráfico 8: Percepção dos docentes sobre o tempo de trabalho na preparação das aulas remotas em comparação às aulas presenciais}

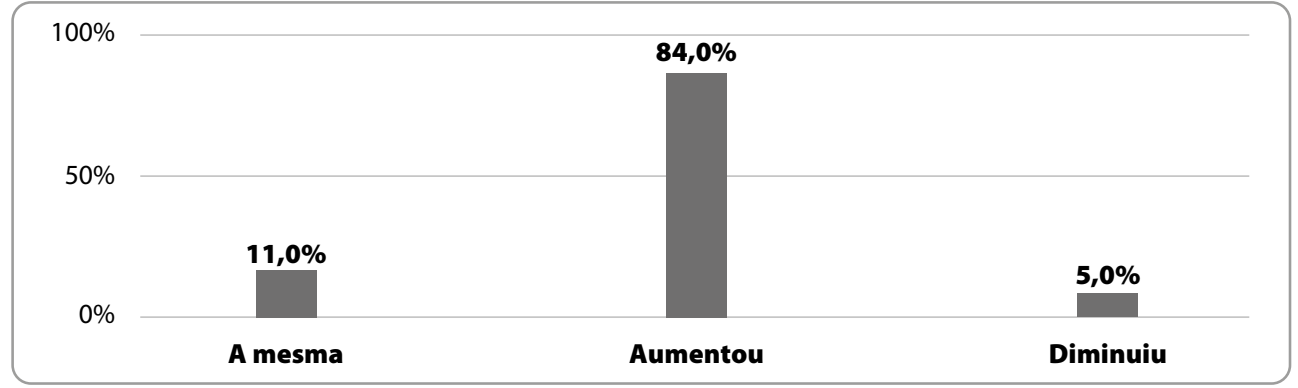

Fonte: Base de dados da pesquisa Trabalho docente em tempos de pandemia do Gestrado, 2020.

Esses dados corroboram com o que temos acompanhado em diversos noticiários, em que os docentes têm relatado sobrecarga e intensificação de trabalho nesse momento de planejamento e desenvolvimento de atividades remotas.

Os docentes, mesmo antes da pandemia, e agora de forma ainda mais intensa, estão imersos em um contexto de trabalho que cada vez mais utiliza mecanismos de autorresponsabilização. E é notória a falta de formação continuada para lidar com tecnologias digitais, evidenciando as precárias condições de trabalho. Somado a isso, observa-se que há falta de apoio das redes de ensino. Oliveira e Vieira (2012) nos chamaram atenção para a intensificação e autointensificação das condições de trabalho dos docentes brasileiros.

Outro lado importante nessa relação de ensino e aprendizagem é o estudante, pois o trabalho docente é uma atividade de interação. Sendo assim, a pesquisa buscou investigar a percepção dos docentes sobre o nível de participação dos estudantes nas atividades propostas.

\section{Gráfico 9: Percepção dos docentes sobre a participação dos estudantes nas atividades propostos remotamente}




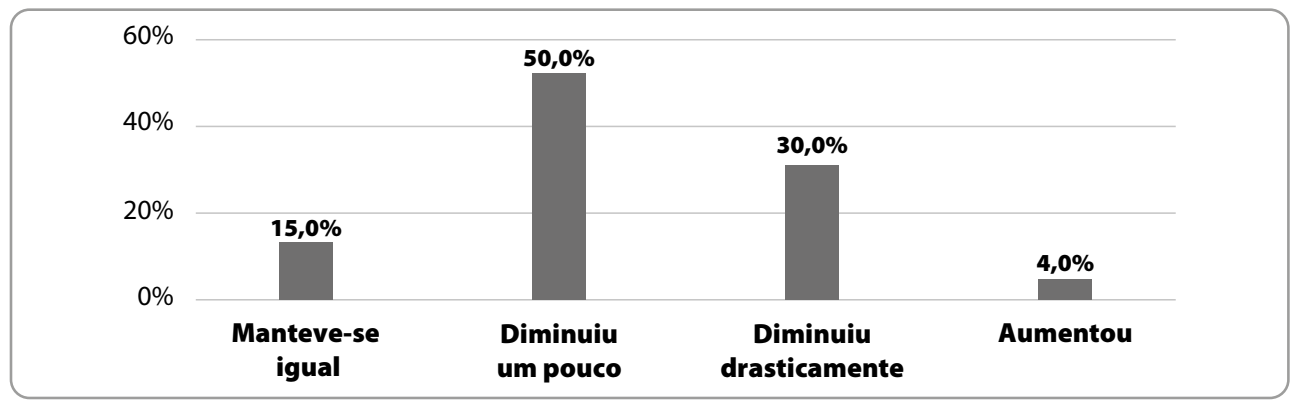

Fonte: Base de dados da pesquisa Trabalho docente em tempos de pandemia do Gestrado, 2020.

Somente $15 \%$ dos professores que participaram da pesquisa avaliaram que não houve perda em relação à participação dos estudantes nas atividades propostas remotamente. Ou seja, o envolvimento dos discentes manteve-se o mesmo e para apenas $4 \%$ dos professores essa participação aumentou.

Contudo, o cenário imposto pelas medidas de isolamento e distanciamento social devido à pandemia da Covid-19 levou a maioria dos professores $(80 \%)$ a perceber que seus estudantes diminuíram um pouco (50\%) ou drasticamente $(30 \%)$ a participação nas atividades propostas (Gráfico 9).

Os dados da pouca participação dos estudantes no cenário brasileiro podem indicar o acirramento das desigualdades sociais, reverberando em desigualdades educacionais e estruturais. Ou seja, neste contexto pandêmico, os estudantes têm deixado de participar do processo educacional e, dessa forma, estão deixando de apreender conhecimentos significativos para sua formação, afetando sua trajetória estudantil.

Com o intuito de compreender as razões que levaram os estudantes a diminuírem suas participações nas atividades propostas à distância, questionamos a percepção dos docentes sobre os principais motivos.

\section{Tabela 1: Percepção dos docentes sobre os motivos da menor participação dos estudantes nas atividades propostas}

\begin{tabular}{ll}
\hline Motivo (múltiplas respostas) & \% \\
\hline As famílias não conseguem auxiliar os estudantes para a realização das atividades. & $72 \%$ \\
\hline Os estudantes não sabem utilizar os recursos tecnológicos para acompanhar as aulas. & $35 \%$ \\
\hline Os estudantes não se sentem motivados para realizar as atividades. & $54 \%$ \\
\hline Os estudantes não têm acesso à internet e aos demais recursos necessários. & $82 \%$ \\
\hline
\end{tabular}

Fonte: Base de dados da pesquisa Trabalho docente em tempos de pandemia do Gestrado, 2020. 
Na percepção geral de $82 \%$ dos docentes, o maior entrave para a participação dos estudantes nas atividades remotas é a falta de acesso à internet e aos demais recursos necessários. Em seguida, 72\% dos docentes afirmam que a baixa participação dos estudantes é devida as famílias não conseguirem auxiliar na realização de atividades escolares. Mais da metade dos professores (54\%) considera que os estudantes não se sentem motivados para participar das atividades remotas. Apenas 35\% dos docentes afirmam que a redução na participação das atividades dos estudantes deve-se a não saberem utilizar os recursos tecnológicos para acompanhar as aulas (Tabela 1).

Essas informações expõem questões importantes da constituição social e educacional no Brasil, a saber: baixo nível educacional dos pais de estudantes que estudam em escolas rurais; insuficiência de acesso à internet e demais recursos necessários para o ensino remoto.

Devido às inúmeras questões neste contexto de pandemia da Covid-19, a pesquisa buscou investigar também o sentimento dos docentes em relação ao momento atual.

\section{Gráfico 10: Sentimento dos docentes em relação ao momento atual}

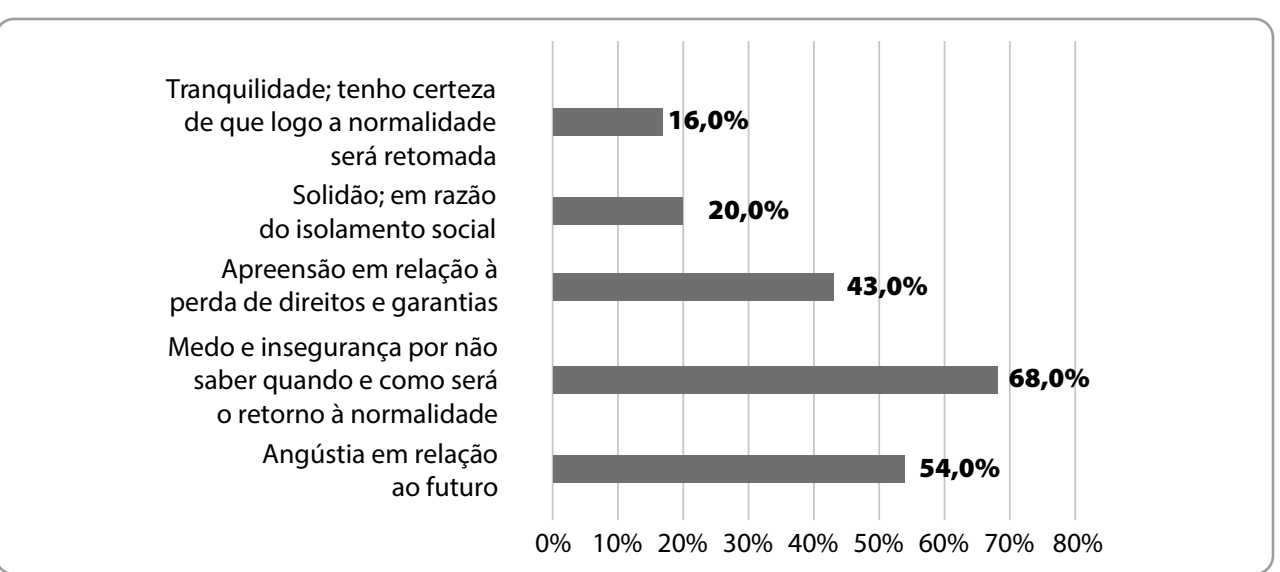

Fonte: Base de dados da pesquisa Trabalho docente em tempos de pandemia do Gestrado, 2020.

A maior parte dos professores (68\%) revela que sente medo e insegurança por não saber quando e como será o retorno às atividades regulares. Mais da metade dos professores (54\%) sinaliza que sente angústia em relação ao futuro. Em seguida, $43 \%$ dos docentes relatam viver de forma apreensiva em relação à perda de direitos e garantias. Cerca de $20 \%$ dos professores informam que estão sozinhos em razão do isolamento social. Por outro lado, 16\% dos docentes afirmam que estão tranquilos e certos de que logo a normalidade será retomada (Gráfico 11).

A análise dos dados evidencia questões fundantes para pensar sobre condições de trabalho dos professores que atuam em escolas do campo em territórios rurais, evidenciando, 
muitas vezes, descaso por parte das secretarias de educação, notadamente, em função de ausência de políticas de formação, de acompanhamento do trabalho docente, gerando intensificação e autorresponsabilização do trabalho.

\section{Considerações finais}

A singularidade da pesquisa Trabalho docente em tempos de pandemia, dada a necessidade de conhecer mais de perto o contexto e os modos como professoras(es) de escolas rurais desenvolvem seus trabalhos, demarca-se na possibilidade de contribuir com leituras de parte da realidade das escolas e dos seus agentes, bem como nas reflexões relacionadas à educação básica pública no Brasil, em especial a que ocorre em escolas rurais.

Compreendemos que a grande amplitude da pesquisa, seja pela quantidade de respondentes, seja pela distribuição por todas as unidades da Federação, assim como a diversidade de informações reveladas pelos docentes, contribui para o conhecimento da realidade das escolas de educação do campo e as condições de trabalho dos professores.

Experienciamos e vivemos uma situação inédita e inesperada, pois as pessoas e os docentes não estavam preparados para enfrentar os desafios acarretados pela pandemia e as medidas de distanciamento e isolamento social, o que de fato gerou reorganizações pessoais, sociais e profissionais, exigindo dos docentes processos de reordenamento do trabalho e o desenvolvimento de atividades remotas, aprendizagens com utilização de plataformas virtuais e aspectos diretamente vinculados à sobrecarga de trabalho.

Dessa forma, os dados da pesquisa nos informam que as redes de ensino públicas que ofertam a educação do campo adotaram diferentes estratégias, desde a oferta de aulas remotas até a elaboração de atividades didáticas para envio às famílias e aos alunos, além da suspensão total das atividades letivas.

Devido ao contexto pandêmico, os professores iniciaram a realização de seu trabalho de forma remota, necessitando adaptar as atividades e desenvolver novas habilidades com as tecnologias digitais. Conforme os dados, o ensino remoto exigiu esforços para grande parte dos professores que não recebeu formação para o desenvolvimento das atividades. Apesar disso, nota-se que muitos deles buscaram de maneira própria processos formativos para orientar o processo de ensino e aprendizagem e desenvolver o trabalho.

Evidenciamos também os problemas históricos que envolvem a educação do campo, a saber: precariedade das escolas; ausência de profissionais suficientes; falta de suporte as unidades educacionais; as questões relacionadas às condições sociais e econômicas das famílias que vivem em contextos rurais, o que potencializa o contexto e o cenário atual face à pandemia e suas consequências para a vida; o enfrentamento das desigualdades; e acirramento de práticas de exclusão social. 
Os resultados desta pesquisa devem provocar novos estudos e análises no âmbito acadêmico, gerando leituras outras e compreensões do modo como os docentes têm vivenciado e enfrentado os desafios na pandemia. Além disso, esperamos que as informações socializadas possam contribuir para a elaboração de políticas públicas que promovam melhoria das condições de trabalho e de vida das populações que residem em contextos rurais.

Recebido em: 15/10/2020 e Aprovado em: 05/11/2020

\section{Referências}

ALMEIDA, Doris Bittencourt. A educação rural como processo civilizador. In: STEPHANOU, Maria et al. (Org.). Histórias e memórias da educação no Brasil. Volume III, século XX. Petrópolis: Vozes, 2005. p. 278-295.

AMIGUINHO, Abilio. Escola em meio rural: uma escola portadora de futuro? Educação, Santa Maria, v. 33, n. 1, p. 11-32, jan./abr. 2008.

ANTUNES-ROCHA, Maria Isabel; HAGE, Salomão Mufarrej. Escola de Direito: ressignificando a escola multisseriada. Belo Horizonte: Autêntica, 2010.

BOF, Alvana Maria (Org). A educação no Brasil rural. Brasília, INEP, 2006.

CARVALHO, Maria Regina Viveiros. Perfil do professor da educação básica. Brasília: INEP. 2018. (Série documental. Relatos de pesquisa, n. 41). Disponível em: http://portal.inep.gov.br/ documents/186968/486324/Perfil+do+Professor+da+Educa\%C3\%A7\%C3\%A3o+B\%C3\%A1sica/ 6b636752-855f-4402-b7d7-b9a43ccffd3e?version=1.2. Acesso em: 5 out. 2020.

FLEURI, Reinaldo Matias. Perfil profissional docente no Brasil: metodologias e categorias de pesquisas. Brasília: Inep, 2015. (Relatos de Pesquisa, n. 40). Disponível em: http://portal.inep.gov.br/ documents/186968/486324/Perfil+Profissional+Docente+no+Brasil+Metodologias+e+Categorias +de+Pesquisas/0265e3d7-3948-4b16-83c6-0b43dc14c6b3?version=1.2. Acesso em: 7 out. 2020.

INEP. Estudo Exploratório sobre o Professor Brasileiro: com base nos resultados do Censo Escolar da Educação Básica 2007. Brasília, 2009. Disponível em:< http://portal.mec.gov.br/dmdocuments/ estudoprofessor.pdf >. Acesso em: 5 out. 2020.

INEP. Sinopse Estatística da Educação Básica 2019. 2020. Disponível em: http://portal.inep.gov.br/basicacenso-escolar-sinopse-sinopse. Acesso em: 5 out. 2020.

INEP. Panorama da educação no campo. Brasília: 2007. Disponível em: http://portal.inep.gov.br/ informacaodapublicacao/asset_publisher/6JYIsGMAMkW1/document/id/490919>. Acesso em 18 de out. 2020 .

MOREIRA, Roberto José. Ruralidades e globalizações: ensaiando uma interpretação. In: MOREIRA, Roberto José (Org.). Identidades sociais: ruralidades no Brasil contemporâneo. Rio de Janeiro: DP\&A, 2005. p. $15-41$. 
OLIVEIRA, Dalila Andrade; VIEIRA, Lívia Fraga. (Org). Trabalho na educação básica: a condição docente em sete estados brasileiros. Belo Horizonte: Fino Traço, 2012.

PNAD. Sintese de indicadores 2014. Brasília: DF, 2014. Disponível em: <http://www.ibge.gov.br>. Acesso em 9 nov. 2020.

PEREIRA JUNIOR, Edimilson Antônio. Condições de trabalho docente nas escolas de educação básica no Brasil: uma análise quantitativa. Tese (Doutorado em Educação, Conhecimento e Inclusão Social) Universidade Federal de Minas Gerais, Belo Horizonte, 2017.

PEREIRA, Ana Claudia da Silva. Condições de funcionamento de escolas do campo: em busca de indicadores de custo-aluno-qualidade. Dissertação (Programa de Pós-graduação do Instituto de Ciências da Educação) Universidade Federal do Pará, Belém, 2008.

RAMOS, Michael Daian Pacheco. Condições de Trabalho Docente de Professores de Escolas Rurais do Território Piemonte da Diamantina-Bahia. Tese. (Doutorado em Educação e Contemporaneidade). Programa de Pósgraduação em Educação e Contemporaneidade, Universidade do Estado da Bahia, Salvador, 2020.

SANTOS, Fábio Josué Souza dos Docência e memória: narrativas de professoras de escolas rurais multisseriadas. Tese (Doutorado em Educação e Contemporaneidade) - Universidade do Estado da Bahia, Salvador, 2015.

SOUSA, Roseane Costa de. Professoras de Classes Multisseriadas: condições de trabalho docente no Território de Identidade do Baixo Sul baiano. Dissertação (Mestrado em Educação e Contemporaneidade). Universidade do Estado da Bahia, Salvador, 2015.

SOUZA, Elizeu Clementino de, et.al. Escola Rural: diferenças e cotidiano escolar. Salvador: EDUFBA, 2017. (Caderno temático 2)

SOUZA, Elizeu Clementino de, et.al. Ruralidades, Ritos de Passagem e Acompanhamento Escolar. Salvador: EDUFBA, 2018.

SOUZA, Elizeu Clementino de; RAMOS, Michael Daian Pacheco Ramos. Indicadores educacionais do Território Piemonte da Diamantina: apontamentos iniciais. Revista de Educação Pública. Cuiabá. V. 28, n. 69. p. 677-699. 2019.

SOUZA, Gildison Alves de. Condições de Trabalho Docente nas Escolas Rurais de Capim Grosso-Bahia. Dissertação (Mestrado em Educação e Contemporaneidade). Programa de Pós-graduação em Educação e Contemporaneidade, Universidade do Estado da Bahia, Salvador, 2020.

UNESCO. O perfil dos professores brasileiros: o que fazem, o que pensam, o que almejam. São Paulo: Moderna, 2004. 